\title{
THE ATTACHED PAYLOAD FACILITY PROGRAM: \\ A FAMILY OF IN-SPACE COMMERCIAL FACILITIES FOR TECHNOLOGY, SCIENCE AND INDUSTRY
}

\author{
Don E. Avery \\ NASA, Langley Research \\ Center \\ Mail Stop 359 \\ Hampton, VA 23681-0001 \\ 757-864-1947
}

\author{
Martin J. Kaszubowski \\ SpaceTec, Inc. \\ 3221 N.Armistead Ave. \\ Hampton, VA 23666 \\ 757-865-0900 \\ Michael E. Kearney \\ SPACEHAB \\ 1331 Gemini Ave., Suite 340 \\ Houston, TX 77058 \\ 713-212-8732
}

\author{
Trevor P. Howard \\ Micro Craft, Inc. \\ 13100 Space Center Blvd. \\ Houston, TX 77059 \\ 713-280-9198 ext. 20
}

\begin{abstract}
It is anticipated that as the utilization of space increases in both the government and commercial sectors there will be a high deg ree of interest in materials and coatings res earch as well as res earch in space environment definition, deploy able structures, multi-functional structures and electronics. The International Space Station (ISS) is an excellent platform for long-term technology development because it provides large areas for external attached payloads, power and data capability, and ready access for experiment exchange and return. An alliance of SPACEHAB, Micro C raft, Inc. and SpaceTec, Inc. has been formed to satisfy this research need through commercial utilization of the capabilities of ISS. The alliance will provide a family of facilities designed to provide low-cost, reliab le access to space for experimenters. This senvice would start as early as 1997 and mature to a fully functional attached facility on ISS by 2001. The alliance's facilities are based on early activities by NASA, Langley Research Center (LaRC) to determine the feasib ility of a Material Exposu re Facility (MEF).
\end{abstract}

\section{INTRODUCTION}

With increased utilization of space for both commercial and non-commercial endeavors there will be increased interest in space effects research concerning materials and coatings, space environment definition, deployable structures, multi-functional structures and electronics experiments. The Long Duration Exp osure Facility's (LDEF) data analy sis continues to provide a wealth of information on the behav ior of materials exposed to the space env ironment. These data have also generated additional questions that need to be answered. LDEF's success indicates the need for extended and improved capability to study the space environment.

The ISS is an excellent platform for long-term technology development because it provides large areas for external attached payloads, power and data capability as well as routine access for experiment exchange and return. To address this research need and capitalize on the ISS capability SPACEHAB, Micro Craft, Inc. and SpaceTec, Inc. have formed an alliance which will develop the Attached Payload Facility Program as a commercial endeavor to provide access to the space environment. 


\section{A FAMILY OF COMMERCIAL FACILITIES}

The family of commercial facilities (Fig. 1) will begin with an expanded use of the Langley Passive Experiment Carrier (PEC) for near-term research on the Shuttle, Mir and the SPACEHAB module rooftop. The PEC was originally built to provide a common carrier with common Shuttle and Mir interfaces for the International Space Station Phase I Risk Mitigation Program environmental experiments. A version of the PEC is currently fly ing as part of the Mir Env ironmental Effects Pay load with a complement of instruments and experiments (See Figure 2). SpaceTec has obtained a Memorandum of Agreement and licensing agreement with NASA that gives the alliance the ability to use the PEC. The alliance intends to offer space access comparable to MEEP using the PEC for a wide variety of research and development experiments.

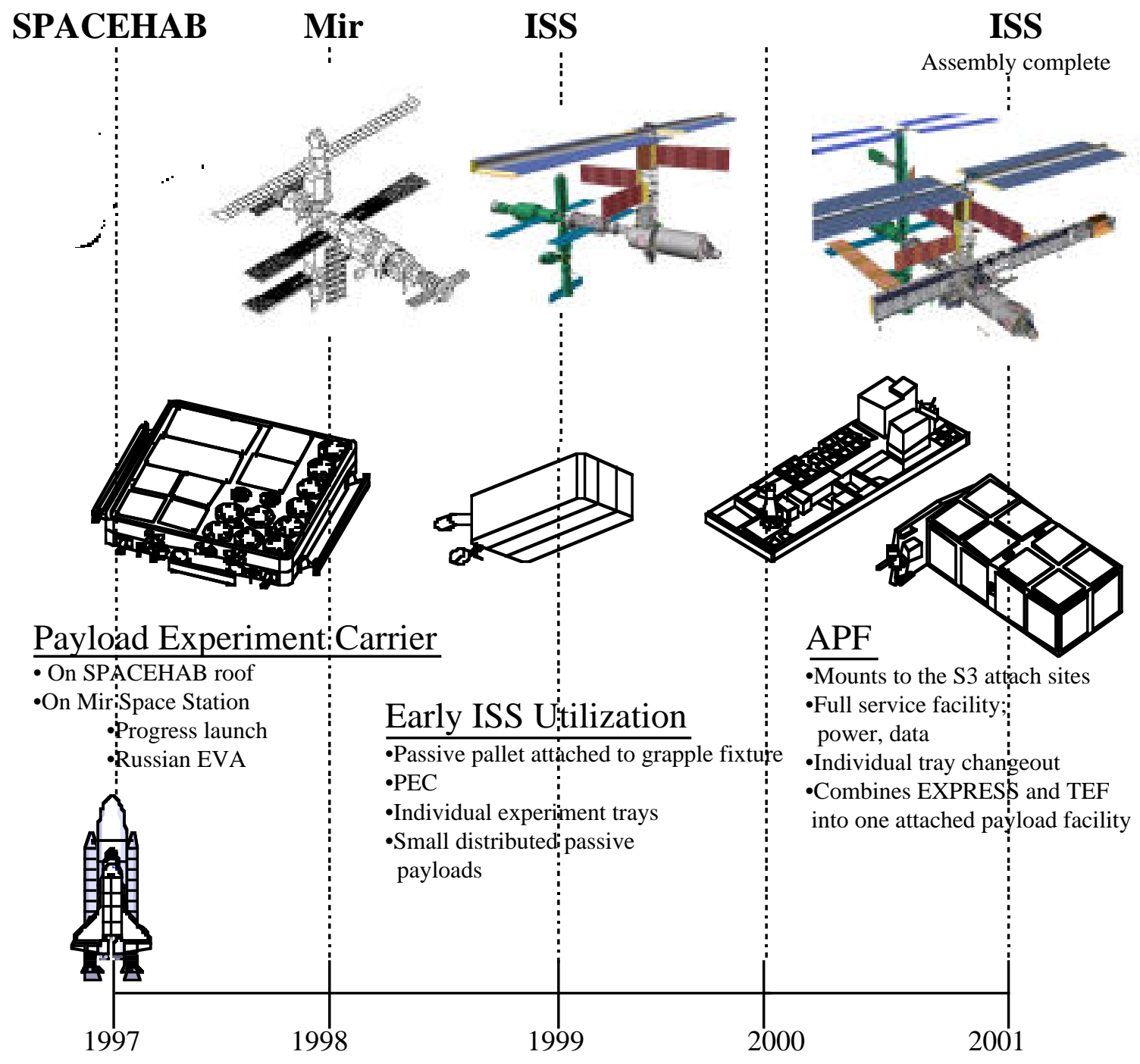

FIGURE 1. A Family of Commercial Space Access Facilities.

A PEC with current hardware can be mounted on the Mir handrails, Shuttle sidewalls, and SPACEHAB module rooftop. The PEC requires EVA installation on the Mir; however, the PEC can be ground integrated for the SPACEHAB module rooftop or the Shuttle sidewall. Once a PEC is installed on any of the above spacecraft, an EVA will be required to open the suitcase-type structure in order to expose the experiments to the space environment. 
As part of its family of commercial facilities, the alliance plans to dev elop an enhanced PEC capability experiment platform. The enhanced PEC will be capable of flying on Shuttle, Mir, SPACEHAB and on ISS. This enhanced PEC will p rov ide power and data interfacs to the experiments if required. SPACEHAB can provide direct power and data interfaces to the PEC and its complement of experiments. Through the use of power and data modules, it is planned to accommodate active experiments on Shuttle, Mir and ISS. The PEC along with the enhanced PEC will provide an excellent opportunity for a robust research program prior to ISS assembly thus facilitating development of experiment systems, processes, and a commercial base in preparation for the ISS. Once ISS is operational, the alliance plans to accelerate early utilization by offering exp eriment access through the use of variants of the PEC and the enhanced PEC that can be attached to the many Flight Releasable Grapple Fixtures to be found on ISS. This EVA installed facility would allow longer duration experiments accommodation very early in the ISS program.

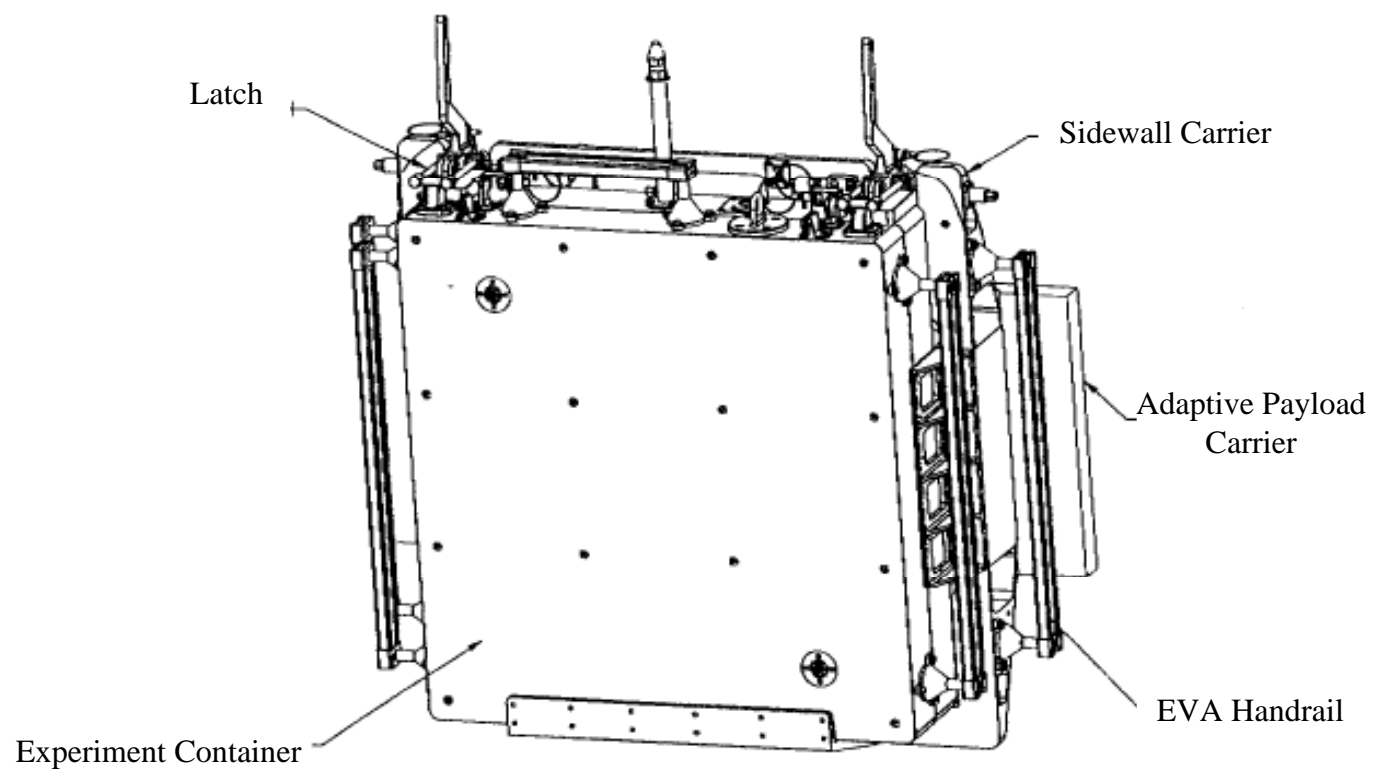

(a) Launch configuration.

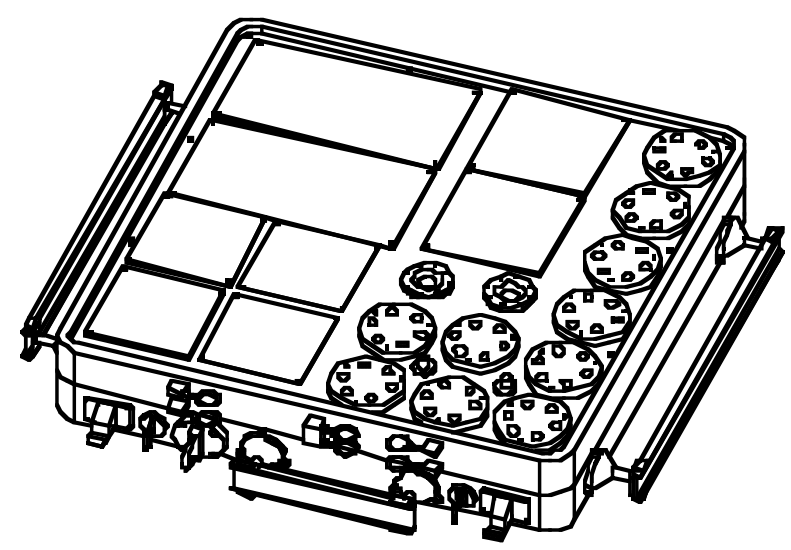

(b) Representative experiment configuration.

FIGURE 2. LaRC MEEP Configuration. 
To complete the family of commercial facilities, the alliance has begun development of an Attached Payload Facility (APF) for use on ISS. The APF is based on the Material Exposure Facility (MEF) concept (Fig. 3) developed under the lead of LaRC and will be a robust facility for external technology, science and industry. A facility such as the APF has several benefits to the current and future space community. These benefits include providing an international engineering testbed in low Earth orb it for conducting long-term space exp osure exp eriments, in-orbit ev aluations of currently used and new spacecraft technologies over the ISS lifetime, data for verification of ground-based lifetime prediction tools of technologies in low Earth orbit and validation and verification of future generation space technology and environment definition models and tools. Candidate technology development experiments that could use this facility include materials exposure, space environment definition, deployable structures, multi-functional structures, electronics experiments, and etc.

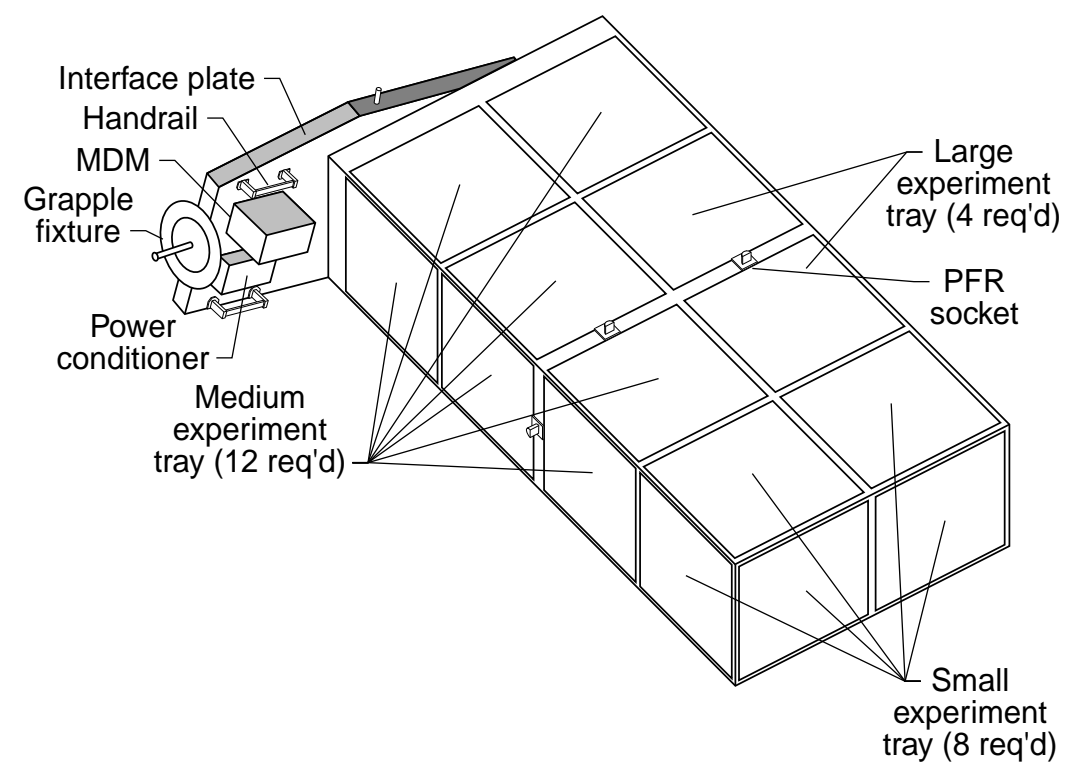

FIGURE 3. Langley Research Center Materials Exposure Facility Concept.

The facility will allow experimenters routine access to the space environment with a system of interchangeable experiment trays and standard interfaces that can provide power and data to each experiment. In addition, the alliance plans to offer the facility users optional services for experiment integration, and experiment operations. The experimenter will be allowed to do the integration and operations if they have access to adequate facilities to accomplish the tasks.

\section{THE COMMERCIAL DEVELOPMENT ALLIANCE}

The structure of the commercial development alliance formed between SpaceTec, Micro Craft and SPACEHAB has not been finalized. However, the alliance is moving forward with the program and the companies have agreed that each company will work the areas consistent with their corporate strategic plan and expertise. NASA, LaRC will be an associate member of the alliance. Currently, the expertise to be contributed by each alliance member is as follows. 


\section{SPACEHAB}

Program Lead

Finance and Marketing

Experiment, Mission and Physical Integration and Operations

\section{SpaceTec}

User Interface

Experiment Development and Preparation

Optional User Services for integration and science operations

Micro Craft

Design Lead

Manufacturing

Sustaining Engineering Support

NASA, Langley Research Center (associate member)

Materials and Structures Center of Excellence

Utilization and Accommodation Analyses

Facility Engineering Advisor

The family of facilities will be financed by the commercial alliance that will not require an anch or tenancy agreement with NASA. A long term cooperative agreement is planned with NASA that will authorize SPACEHAB, Micro C raft and SpaceTec to operate a commercial attached payload service. Terms of this agreement have not been negotiated at this time.

\section{SCHEDULE AND COST}

With the current manifesting schedule, the first opportunity for a launch of PEC will be mid 1997. Consistent with the ISS Assembly Sequence Revision B, the first opportunity for an APF launch is early 2001. How ever, because of the family of facilities planned, a robust external exp eriment program can be continuously maintained until the APF is launched. The planned NASA cooperative agreement will identify all the research opportunities.

The price of launching an exp eriment on the alliance's commercial facilities will dep end on the ability to negotiate a long-term cooperative agreement with NASA. The agreement must clarify transp ortation cost and ISS resource (power, data, and etc.) availability and cost. A primary goal is to negotiate a cost as low as possible in order to offer as low a price as possible for using the commercial facilities.

\section{SUMMARY}

SPACEHAB, Micro Craft and SpaceTec have formed an aliance to expand upon the work started by LaRC on the Materials Exposure Facility and take on the challenge of providing a family of commercial facilities for conducting space res earch and technology dev elopment. The alliance's final goal will be the development of the Attached Payload Facility for the International Space Station. Candidate technology development experiments that could use these facilities encompass materials exposure, space environment definition, deployable structures, multi-functional structures, and electronics experiments. With the current manifesting schedule, the first launch opportunity for this family of facilities will be in 1997. 
The SPACEHAB, Micro Craft and SpaceTec alliance is dedicated to developing a viable commercial attached payload service that reliably meets the needs of the U.S. government, international governments, universities, and industry at the lowest possible price. 